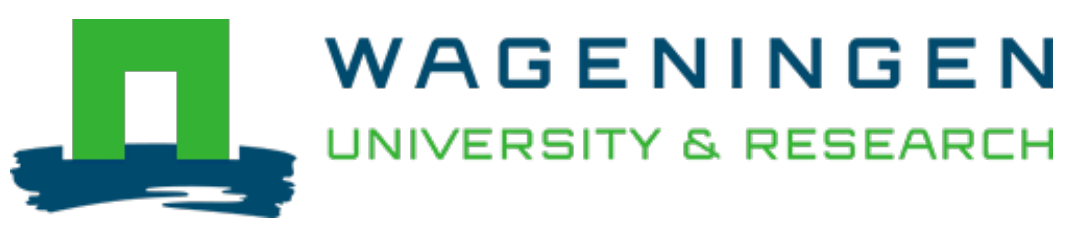

\title{
Response of metal-coordination-based polyelectrolyte complex micelles to added ligands and metals
}

\section{Soft Matter}

Wang, Junyou; Guan, Wenjun; Tan, Tianhong; Saggiomo, Vittorio; Cohen Stuart, Martien A. et al https://doi.org/10.1039/c9sm02386k

This article is made publicly available in the institutional repository of Wageningen University and Research, under the terms of article $25 \mathrm{fa}$ of the Dutch Copyright Act, also known as the Amendment Taverne. This has been done with explicit consent by the author.

Article 25 fa states that the author of a short scientific work funded either wholly or partially by Dutch public funds is entitled to make that work publicly available for no consideration following a reasonable period of time after the work was first published, provided that clear reference is made to the source of the first publication of the work.

This publication is distributed under The Association of Universities in the Netherlands (VSNU) 'Article $25 \mathrm{fa}$ implementation' project. In this project research outputs of researchers employed by Dutch Universities that comply with the legal requirements of Article $25 \mathrm{fa}$ of the Dutch Copyright Act are distributed online and free of cost or other barriers in institutional repositories. Research outputs are distributed six months after their first online publication in the original published version and with proper attribution to the source of the original publication.

You are permitted to download and use the publication for personal purposes. All rights remain with the author(s) and / or copyright owner(s) of this work. Any use of the publication or parts of it other than authorised under article $25 \mathrm{fa}$ of the Dutch Copyright act is prohibited. Wageningen University \& Research and the author(s) of this publication shall not be held responsible or liable for any damages resulting from your (re)use of this publication.

For questions regarding the public availability of this article please contact openscience.library@wur.nl 


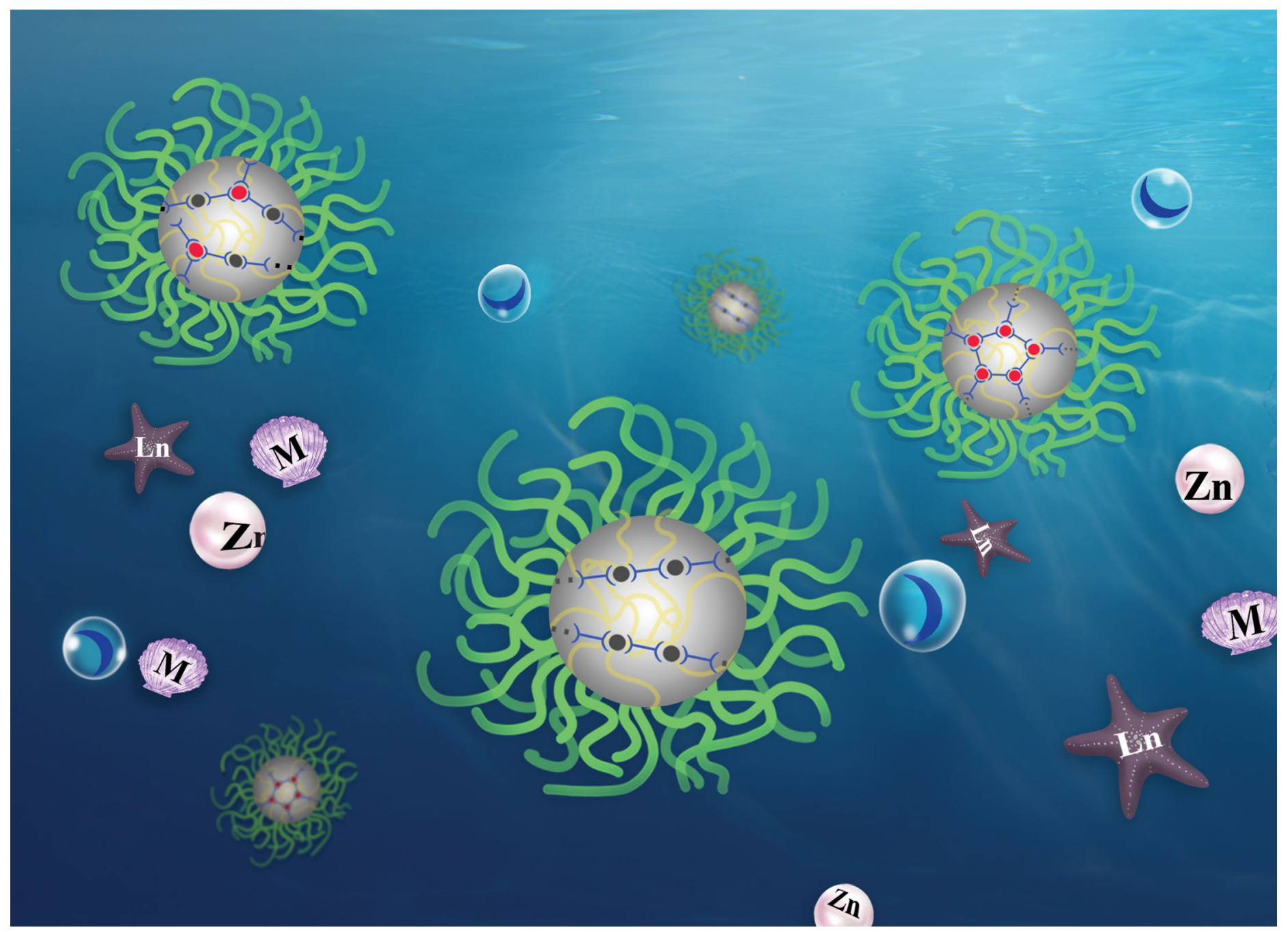

Highlighting research from the collaboration between the group of Dr Junyou Wang from School of Chemical Engineering at East China University of Science and Technology, and the BioNanoTechnology group of Prof. Aldrik H. Velders at Wageningen University.

Response of metal-coordination-based polyelectrolyte complex micelles to added ligands and metals

Dynamic properties of polyelectrolyte complex micelles, particularly component exchange with other surrounding molecules, have remained elusive to date. The current work shows how micelles based on metal-ligand coordination complex coacervate-core micelles (M-C3Ms) respond to addition of extra ligand and metal ions.

\section{As featured in:}

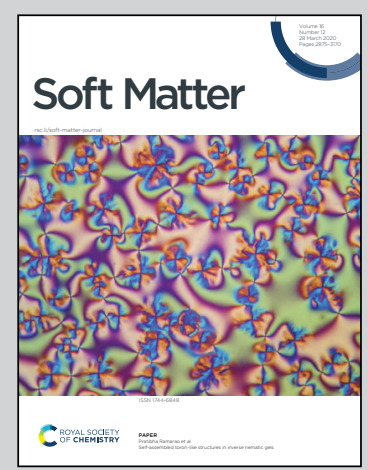

See Junyou Wang,

Aldrik H. Velders et al.,

Soft Matter, 2020, 16, 2953. 
Check for updates

Cite this: Soft Matter, 2020, 16, 2953

Received 3rd December 2019, Accepted 24th February 2020

DOI: $10.1039 / \mathrm{c} 9 \mathrm{sm} 02386 \mathrm{k}$

rsc.li/soft-matter-journal

\title{
Response of metal-coordination-based polyelectrolyte complex micelles to added ligands and metals $\dagger$
}

\author{
Junyou Wang, (D) *ab Wenjun Guan, ${ }^{a}$ Tianhong Tan, ${ }^{a}$ Vittorio Saggiomo, (D) ${ }^{b}$ \\ Martien A. Cohen Stuart (iD ${ }^{a}$ and Aldrik H. Velders (iD $* b$
}

\begin{abstract}
Polyelectrolyte complex based micelles have attracted significant attention due to their potential regarding bio-applications. Although the morphology and functions have been studied extensively, dynamic properties, particularly component exchange with other surrounding molecules, have remained elusive to date. Here, we show how micelles based on metal-ligand coordination complex coacervate-core micelles (M-C3Ms) respond to addition of extra ligand and metal ions. The micelles are prepared from a polycationic-neutral diblock copolymer and an anionic coordination polyelectrolyte, which is obtained by coordination between metal ions (lanthanides $\mathrm{Ln}^{3+}$ and $\mathrm{Zn}^{2+}$ ) and a bis-ligand (LEO) containing two dipicolinic acid (DPA) groups connected by a tetra-ethylene oxide spacer (4EO). Our findings show that the bis-ligand LEO is essential for the growth of coordination polymers and consequently the formation of micelles, leading to equilibrium structures with the same micellar composition and structure independent of the order of mixing. In other words, adding single DPA has no effect on the formed M-C3Ms. As for metal exchange, we find that added $\mathrm{Zn}^{2+}$ can replace some of the $\mathrm{Ln}^{3+}$ from $\mathrm{Ln}$-C3Ms, leading to a hybrid coordination structure with both $\mathrm{Ln}^{3+}$ and $\mathrm{Zn}^{2+}$. We find that component exchange occurs in these coordination polyelectrolyte micelles, but it is more favorable in the direction of replacing the weak binding components with strong ones. Hence, the designed $\mathrm{M}-\mathrm{C} 3 \mathrm{Ms}$ based on the strong binding components, such as Ln-C3Ms, shall be relatively stable in biological surroundings, paving the way for the application of such particles as bio-imaging probes.
\end{abstract}

\section{Introduction}

Polyelectrolyte complex coacervate-core micelles (C3Ms) are nanostructures that owe their existence to the electrostatic attraction between polyion-neutral diblock copolymers and oppositely charged polyelectrolytes. ${ }^{1,2}$ Since the first report on such micelles in the mid-90's, these objects have attracted considerable attention due to their great potential in bio-applications, and extensive investigations followed. ${ }^{3-5}$ Although good control of the morphology and functions has been achieved, knowledge of the internal structure and the dynamic properties of these micelles' subcomponents is still limited; in particular, exchange of the ionic components with competing ions in solution is relevant, e.g., in the context of biological fluids. Unfortunately,

\footnotetext{
${ }^{a}$ State Key Laboratory of Chemical Engineering, and Shanghai Key Laboratory of Multiphase Materials Chemical Engineering, East China University of Science and Technology, 130 Meilong Road, Shanghai 200237, People's Republic of China. E-mail: junyouwang@ecust.edu.cn

${ }^{b}$ Laboratory of BioNano Technology, Wageningen University, Bornse Weilanden 9, 6708 WG Wageningen, The Netherlands. E-mail: aldrik.velders@wur.nl

$\dagger$ Electronic supplementary information (ESI) available. See DOI: 10.1039/c9sm02386k
}

conventional techniques to study exchange encounter problems because of the intrinsic properties of the micelles. ${ }^{6}$ The hydrated building blocks introduce significant amounts of water into the micellar core, and consequently there is low contrast in imaging and scattering. ${ }^{7}$ Moreover, charge-driven formation of micelles implies a large degree of charge compensation; ${ }^{8}$ in particular, the assembly of common synthetic polyelectrolytes shows a sharply defined preferred composition around charge stoichiometry and hardly tolerates an excess of any of the charged components. ${ }^{9,10}$ This makes the study of dynamic exchange of components by adding extra polyelectrolyte to the solution much more challenging. Nevertheless, understanding the dynamics of component exchange is very crucial for application of polyelectrolyte micelles, particularly for bio-applications, because of the presence of many competitive components in the surrounding fluid. ${ }^{11}$ As an example, polyelectrolyte micelles designed for drug/ gene delivery are typically cross-linked after formation, for an enhanced stability that is required for in vivo applications. ${ }^{12,13}$ Progress therefore relies on a novel experimental design that allows investigation of the internal details and dynamic properties of polyelectrolyte micelles. 
We propose the following approach. Some time ago, we reported a novel type of polyelectrolyte micelles based on a polycationic-neutral diblock copolymer, and a polyanionic coordination polymer, which is obtained by coordination between metal ions and a bis-ligand containing two dipicolinic acid (DPA) moieties connected by a tetra-ethylene oxide spacer (4EO). ${ }^{14,15}$ We call these micelles 'metal-containing complex coacervate core micelles', for short M-C3Ms. Unlike micelles formed by organic, (bio)macromolecular polyelectrolytes, M-C3Ms contain hundreds of metal ions in their micellar core. The enhanced contrast arising from these heavy elements makes the M-C3Ms clearly visible under the electron microscope. ${ }^{16}$ Moreover, introducing metal ions not only provides novel functional properties, e.g., magnetic and fluorescence properties from lanthanides, but also introduces probes for investigating the internal structure using, e.g., the optical spectrum and fluorescence life time. ${ }^{17-20}$ More importantly, we find that these micelles do not have a narrow range of preferred composition: an excess of coordination complexes in solution cannot undo the coacervation needed for micellization, because the supramolecular polyelectrolytes are reversible structures that predominantly form inside the micellar core. ${ }^{21}$ This behavior is totally different for polyelectrolyte micelles in which the corepolyelectrolyte consists of normal polymers, and an excess or shortage of that with respect to the second (block copolymer) polyelectrolyte will destabilize the micellar structure. ${ }^{8}$ This asymmetric effect offers us a good system to explore the dynamics of micelles by recording their response to added extra components, and this is discussed in detail in the present work. Although the current study focuses on a special case of polyelectrolyte micelles, it reveals for the first time the occurrence of component exchange in polyelectrolyte complex core micelles. Our study will inspire the design of more investigations in this direction to shed light on the dynamic properties of polyelectrolyte micelles, and thereby take a next step towards the application of such particles in complex, e.g. biological, settings.

\section{Results and discussion}

The molecular system involved in this study is shown in Scheme 1. Bis-ligand and 4-hydroxypyridine-2,6-dicarboxylic acid are presented as LEO and DPA, respectively. The diblock copolymer (BP), $\mathrm{P}_{2} \mathrm{MVP}_{128}-b-\mathrm{PEO}_{477}$, has a linear structure and a fixed number of charges, independent of the $\mathrm{pH}$, due to its pyridinium groups. In the absence of the block copolymer, the coordination structure and overall negative charges of the metal and bis-ligand (M-LEO) depend on concentration and the $\mathrm{M} / \mathrm{LEO}$ ratio. Monomeric and short oligomeric complexes are predominantly present at low concentrations of M-LEO, whilst coordination polymers are formed at high concentrations. ${ }^{22}$ Upon mixing with the cationic blocks, the local concentration of M-LEO in the assemblies increases hundreds of times, which dramatically shifts the equilibria of the coordination structures towards coordination polymers. ${ }^{23,24}$ In this study, the $\mathrm{Zn} / \mathrm{LEO}$ ratio is kept at $1 / 1$, at which $\mathrm{Zn}$-LEO can form linear coordination polymers, such that each coordination site carries a net charge of -2 . For lanthanides (Ln), we fix the Ln/LEO ratio at 1/1.5, thereby producing $3 \mathrm{D}$ network structures such that each coordination unit carries 3 negative charges ${ }^{26}$ (Scheme 1). These anionic coordination polymers assemble strongly with the cationic $\mathrm{P}_{2} \mathrm{MVP}_{128}-b-\mathrm{PEO}_{477}$ copolymers and provide well-controlled polyelectrolyte micelles (M-C3Ms), with a core with a linear supramolecular polymer in the case of $\mathrm{Zn}$, and branched supramolecular polymer in the case of Ln. This has no major consequences on the size of the micelles. In the following experiments, we focus on the response of M-C3Ms to either added DPA or excess metal ions, according to various scenarios regarding the order of addition of the different components.

Scheme 2 demonstrates the various scenarios, that is, the different preparation routes to arrive at the micellar system, in order to investigate whether there is an exchange of LEO and DPA. We first prepared the micelles with LEO (mixture A), then challenged the micelles by adding DPA to the micelle solution (keeping the total amount of ligand the same); the final state is indicated as $\mathrm{A}^{\prime}$. Alternatively, we could also mix the metal ions, DPA and BP, (B) then add LEO to the mixture $\left(\mathrm{B}^{\prime}\right)$ and record the changes undergone by the system. Finally, we first mix metal ions, LEO and DPA, (C) and then add BP to the mixture to obtain $\mathrm{C}^{\prime}$, and see which ligand (LEO or DPA) is selected to be taken up into the micelles. Obviously, $\mathrm{A}^{\prime}, \mathrm{B}^{\prime}$ and $\mathrm{C}^{\prime}$ have the same overall composition of components in solution, but they are obtained by different preparation routes. Specifically, stock solutions were prepared first, then designed amounts of different components were selected and mixed for the formation of the micelles and the study of LEO-DPA exchange (ESI, $\dagger$ sample preparation). Given as an example, for A and $\mathrm{A}^{\prime}$ samples, we prepared them separately. Sample A was prepared by taking the designed volumes of different components. For sample $\mathrm{A}^{\prime}$, all the components except for the DPA were mixed first, and the obtained micelle solution was left for 1 hour to equilibrate completely. Then, DPA that contained the same amount of chelate groups as that of LEO was added to the solution, followed by 1-2 min vortex and another hour of equilibration before the analysis. Samples for scenario B and C were prepared by the same method.

We first consider lanthanum-containing micelles, La-C3Ms. Fig. 1 shows that La-LEO together with diblock copolymers (A) forms micelles with a hydrodynamic radius of around $22 \mathrm{~nm}$, and a narrow size distribution. Adding DPA $\left(\mathrm{A}^{\prime}\right)$ has no effect on either the light scattering intensity or the size distribution. In system $\mathrm{B}$, the mixture with $\mathrm{La}^{3+}$, DPA and $\mathrm{BP}$, without the bis-ligand, shows no scattering intensity, which means that there is no aggregation or formation of micelles in that solution. Upon adding LEO to the mixture $\left(\mathrm{B}^{\prime}\right)$, the intensity rises sharply, reaching a value similar to that of La-C3Ms (A and $\mathrm{A}^{\prime}$ ). Finally, the La-LEO-DPA mixture (C) also shows no light scattering intensity, while adding $\mathrm{BP}\left(\mathrm{C}^{\prime}\right)$ leads to a comparable intensity and size to that in $\mathrm{A}^{\prime}$ and $\mathrm{B}^{\prime}$, indicating that similar micelles are formed in the solution. All these results suggest that La-DPA oligomers (DPA-coordinated $\mathrm{La}^{3+}$ ) cannot induce micellization; micelles only form with the LEO 
a

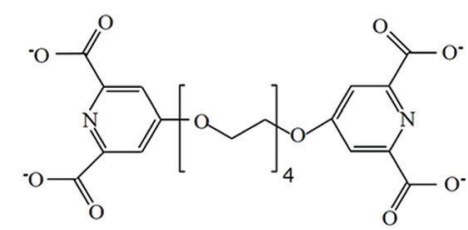

LEO<smiles>COC(=O)c1cc(O)cc(C(=O)O)n1</smiles>

DPA<smiles></smiles>

BP

b

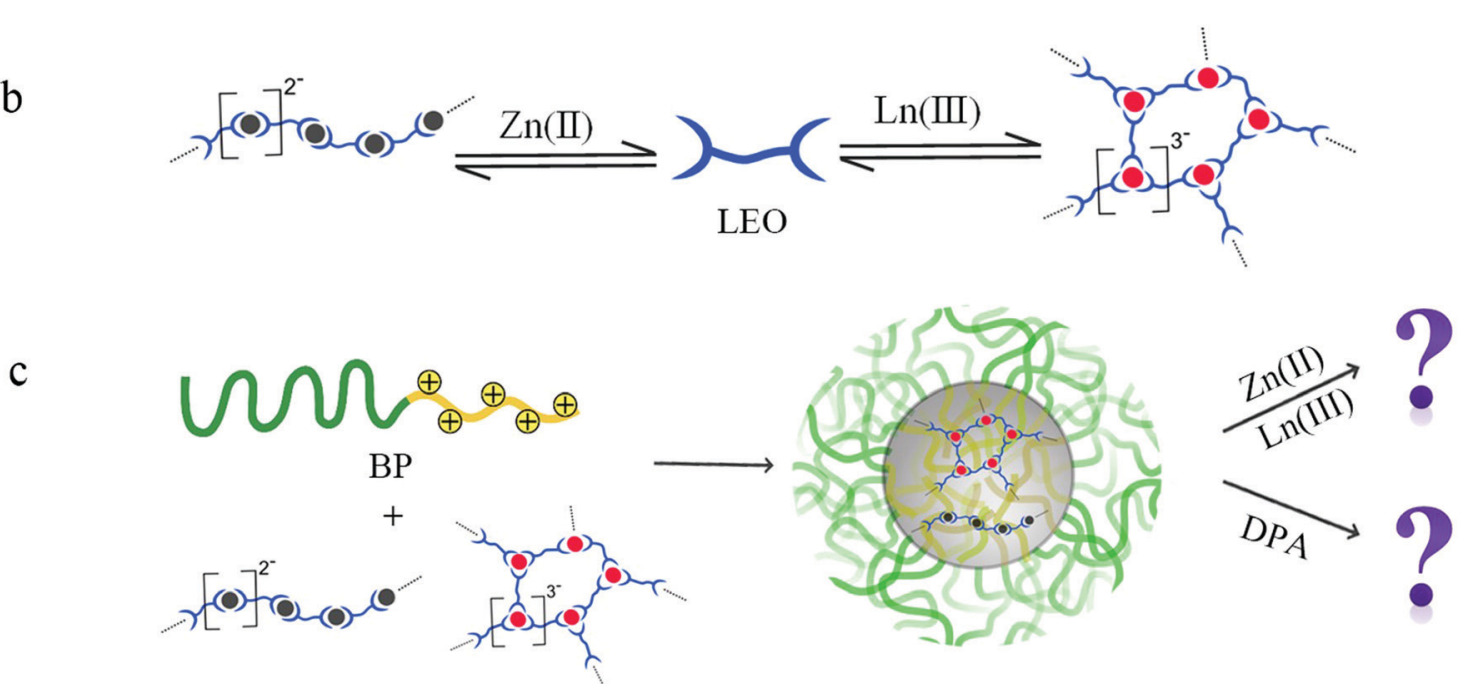

Scheme 1 (a) Structure of the molecules: bis-ligand (LEO), mono-ligand (DPA) and block copolymer P2MVP128-b-PEO 477 . (b) Different coordination structures formed by the metal and LEO, (c) micelle formation, metal and ligand exchange of the polyelectrolyte micelles. Black and red dots represent $\mathrm{Zn}^{2+}$ and $\mathrm{Ln}^{3+}$ metal ions, respectively.
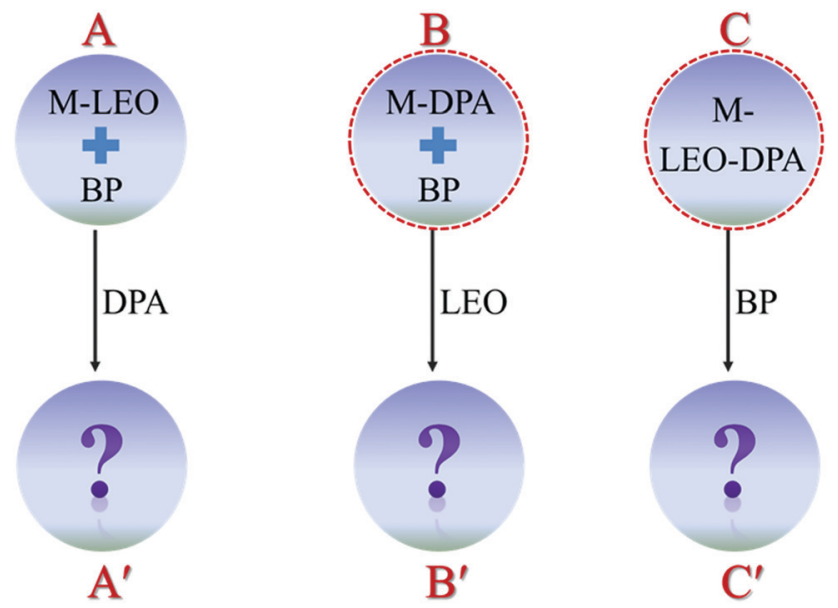

Scheme 2 Different scenarios to prepare micelles and investigate LEO-DPA exchange of M-C3Ms. Note that A starts with micelles in solution, while $B$ and $C$ (dotted circles) could not form micelles with the designed composition. For micelle preparation and exchange details, see the ESI. $\dagger$

bis-ligand that has coordination sites on both ends and therefore allows coordination polymers to form. ${ }^{25,26}$

The light scattering data clearly prove that micelles always select the LEO bis-ligand, independently of the preparation routes. This still leaves the question whether DPA is found inside the micelle, or entirely free in the solution. To answer this question, we performed ${ }^{1} \mathrm{H}$ NMR measurements with an internal standard (TSP) to collect not only chemical shifts but also quantitative intensity information regarding the components in the solution. Note that the components inside the micelles cannot be detected due to the long rotation correlation time of the micelles, leading to extensive peak broadening that effectively removes these signals from the high-resolution spectrum. In other words, only the free LEO or DPA is observed from the ${ }^{1} \mathrm{H}$ NMR spectrum. For the La-LEO-BP mixture (A), the proton of pyridine on LEO is invisible in the ${ }^{1} \mathrm{H}$ NMR spectrum of the La-C3Ms solution, indicating that all the LEO is encapsulated in the micelles. Adding DPA into the solution hardly disturbs the LEO, while a new peak appears at $7.1 \mathrm{ppm}$ from the proton of DPA; from the integrated intensity, we conclude that almost all the added DPA is free in the solution (Fig. S2, ESI $\dagger$ and Table 1). For the La-DPA-BP mixture (B), where the light scattering shows no micelle formation, the ${ }^{1} \mathrm{H}$ NMR spectrum shows only around $57 \%$ DPA free in the solution, indicating that a part of the La-DPA complexes is associated with $\mathrm{P}_{2} \mathrm{MVP}_{128}-b-\mathrm{PEO}_{477}$ chains, which induces a decrease of the NMR signals of DPA. Interestingly, the complete release of DPA takes place after adding LEO to the mixture, indicating that LEO can displace DPA from the coordination structures, thereby inducing micellization; as a result, $98 \%$ DPA is released free into the solution (Fig. 2, Fig. S3, ESI $\dagger$ and Table 1).

In scenario $\mathrm{C}$, the La-LEO-DPA mixture produces both 'free' LEO and DPA signals, indicating the presence of 'free' 

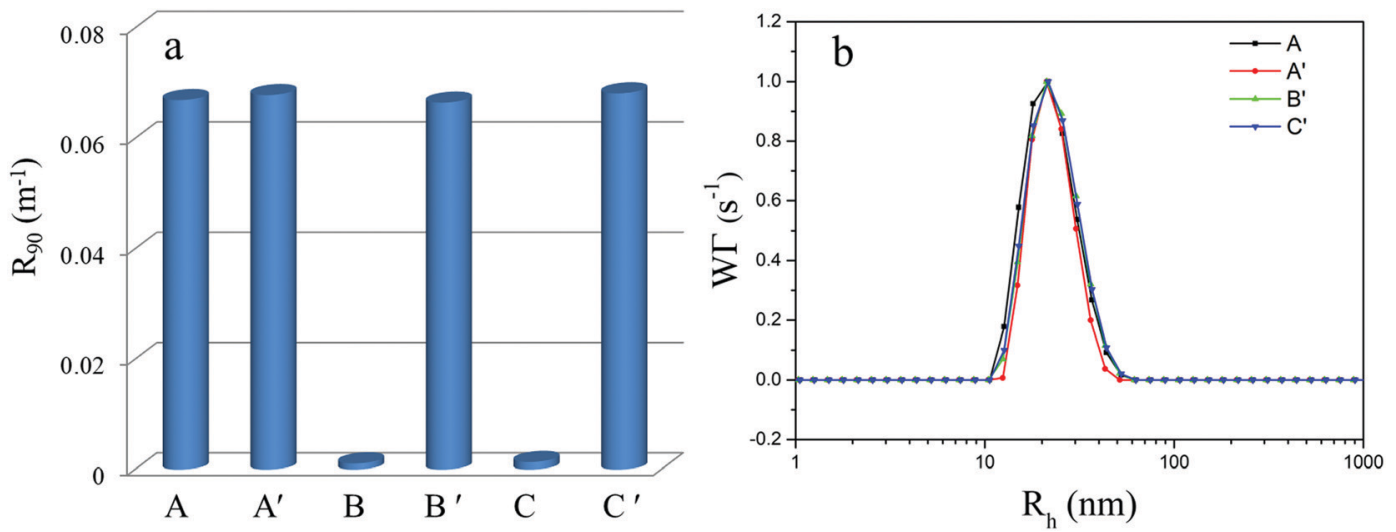

Fig. 1 (a) Light scattering intensity of different La-C3Ms and mixtures. (b) CONTIN analysis of the size and size distribution of the different La-C3Ms and mixtures. No micelles form in $\mathrm{B}$ and $\mathrm{C}$ mixture solutions, so, there is no size information.

Table 1 Fractions of free DPA and LEO in different La-C3Ms and mixture solutions. The amounts are based on the integrals in the ${ }^{1} \mathrm{H}$ NMR spectrum with TSP as an internal standard. ' $/$ ' indicates no NMR signals due to the absence of the compound and ' - ' means hardly detectable integral. For calculation details, see the ESI

\begin{tabular}{lllllll}
\hline & $\mathrm{A}$ & $\mathrm{A}^{\prime}$ & $\mathrm{B}$ & $\mathrm{B}^{\prime}$ & $\mathrm{C}$ & $\mathrm{C}^{\prime}$ \\
\hline DPA & $/$ & $98 \%$ & $57 \%$ & $98 \%$ & $93 \%$ & $91 \%$ \\
LEO & - & - & $/$ & - & $96 \%$ & -
\end{tabular}

(fast rotating, small) coordination structures in the solution, probably a mix of different monomeric and oligomeric complexes.
Adding BP leads to a final solution with no free LEO but $91 \%$ free DPA, which is consistent with the light scattering result that LEO is required to form micelles (Fig. 2, Fig. S4, ESI $\dagger$ and Table 1). In other words, all DPA, even though it can form coordination structures with $\mathrm{La}^{3+}$, remains free in the solution as soon as there is LEO, which implies that it has no effect on the formation of La-C3Ms.

Let us now turn our attention to coordinated $\mathrm{Zn}^{2+}$, and study the LEO-DPA exchange with Zn-C3Ms. As shown in Fig. 3, $\mathrm{Zn}$-LEO-BP forms micelles with a hydrodynamic radius of about $26 \mathrm{~nm}$. Adding DPA to the solution neither changes the

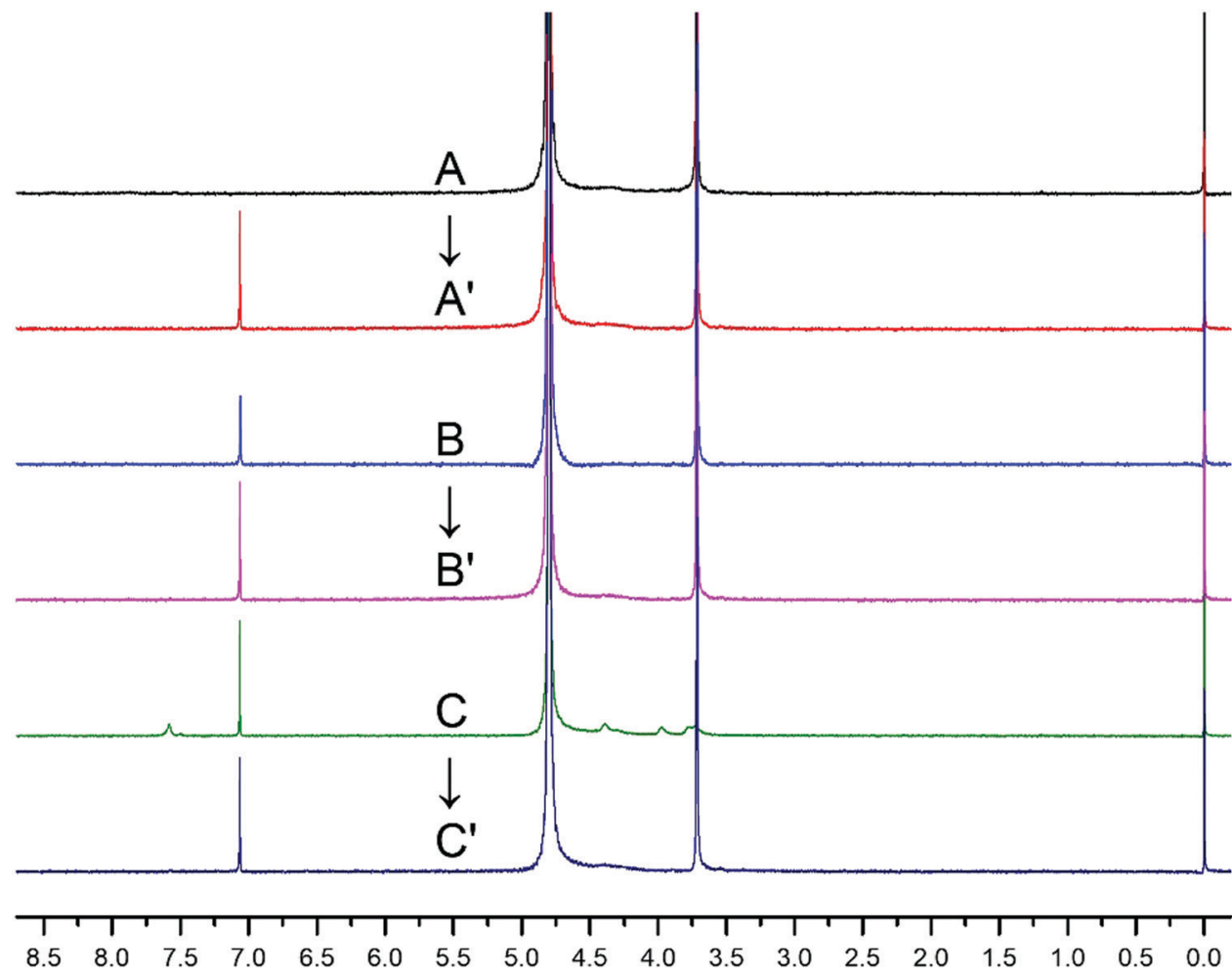

Fig. $2{ }^{1} \mathrm{H}$ NMR spectra of different La-C3Ms and mixtures. All samples were prepared in $\mathrm{D}_{2} \mathrm{O}$ under the designed combination with TSP as an internal standard. 

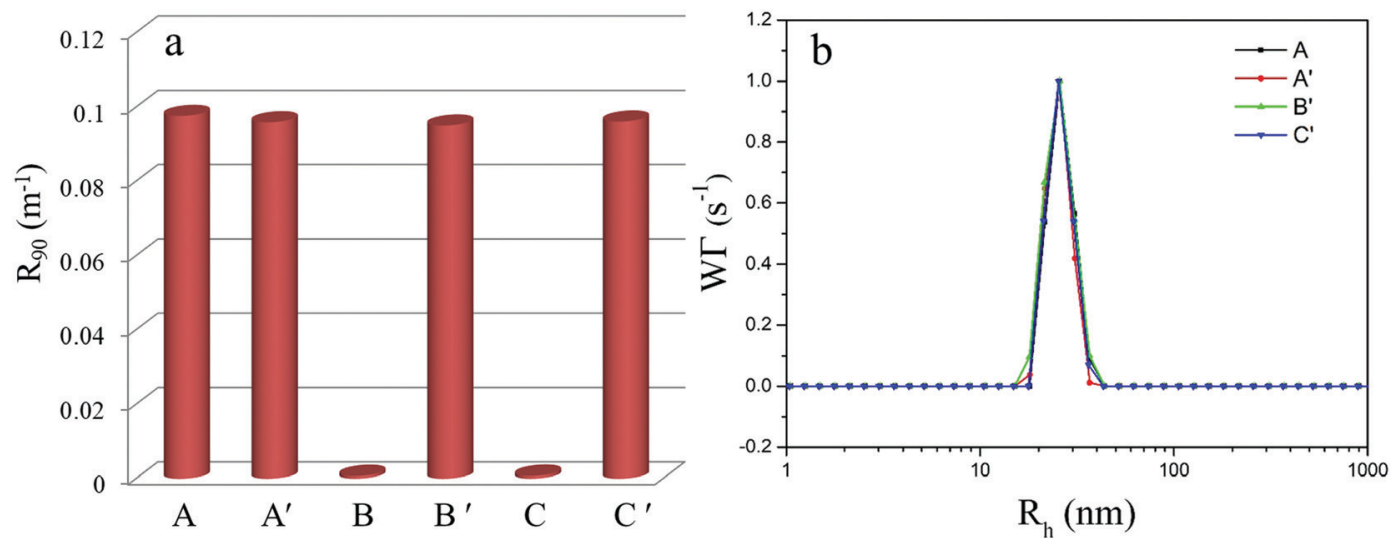

Fig. 3 (a) Light scattering intensity of different Zn-C3Ms and mixtures. (b) CONTIN analysis of the size and size distribution of the different Zn-C3Ms. No micelles form in $B$ and $C$ mixture solutions, so there is no size information.

light scattering intensity $\left(\mathrm{A}^{\prime}\right)$ nor the size and size distribution. This finding confirms that the DPA hardly affects the formed micelles. For case B, the Zn-DPA-BP mixture, we did not find any LEO in the mixture $\left(\mathrm{B}^{\prime}\right)$, which agrees well with what happens for La-C3Ms. Also, scenario $\mathrm{C}^{\prime}$ ends up with similar intensity and size as $\mathrm{A}^{\prime}$ and $\mathrm{B}^{\prime}$.

Fig. 4 shows the NMR spectra of Zn-C3Ms corresponding to LEO-DPA exchange measurements. A Zn-LEO-BP micelle solution gives hardly any free LEO in the mixture, which does not change upon adding DPA in the solution $\left(\mathrm{A}^{\prime}, \mathrm{Fig}\right.$. S5, ESI $\dagger$ and Table 2). Meanwhile, a new peak at $7.2 \mathrm{ppm}$ appears, indicating that around 99\% DPA is free in the solution. For Zn-DPA-BP mixtures, (B) the broad 7.4 ppm peak indicates that the Zn-DPA complexes may not be free in the solution, but most likely associated with $\mathrm{P}_{2} \mathrm{MVP}_{128}-b$ - $\mathrm{PEO}_{477}$ chains creating macromolecule-aggregates with a relatively long correlation time. It is not unlikely that the $\mathrm{Zn}^{2+}$ ions can coordinate to the nonquaternized pyridine moieties present in the BP. The quaternization degree of $87 \%$ leaves plenty of opportunity for the $\mathrm{Zn}^{2+}$ ions to coordinate. Micelles form upon adding LEO into the mixture, leaving 96\% DPA outside the micelles ( $\mathrm{B}^{\prime}$, Fig. S6, ESI $\dagger$ and Table 2). Scenario $\mathrm{C} / \mathrm{C}^{\prime}$ (Fig. S7, ESI $\dagger$ and Table 2) suggests that
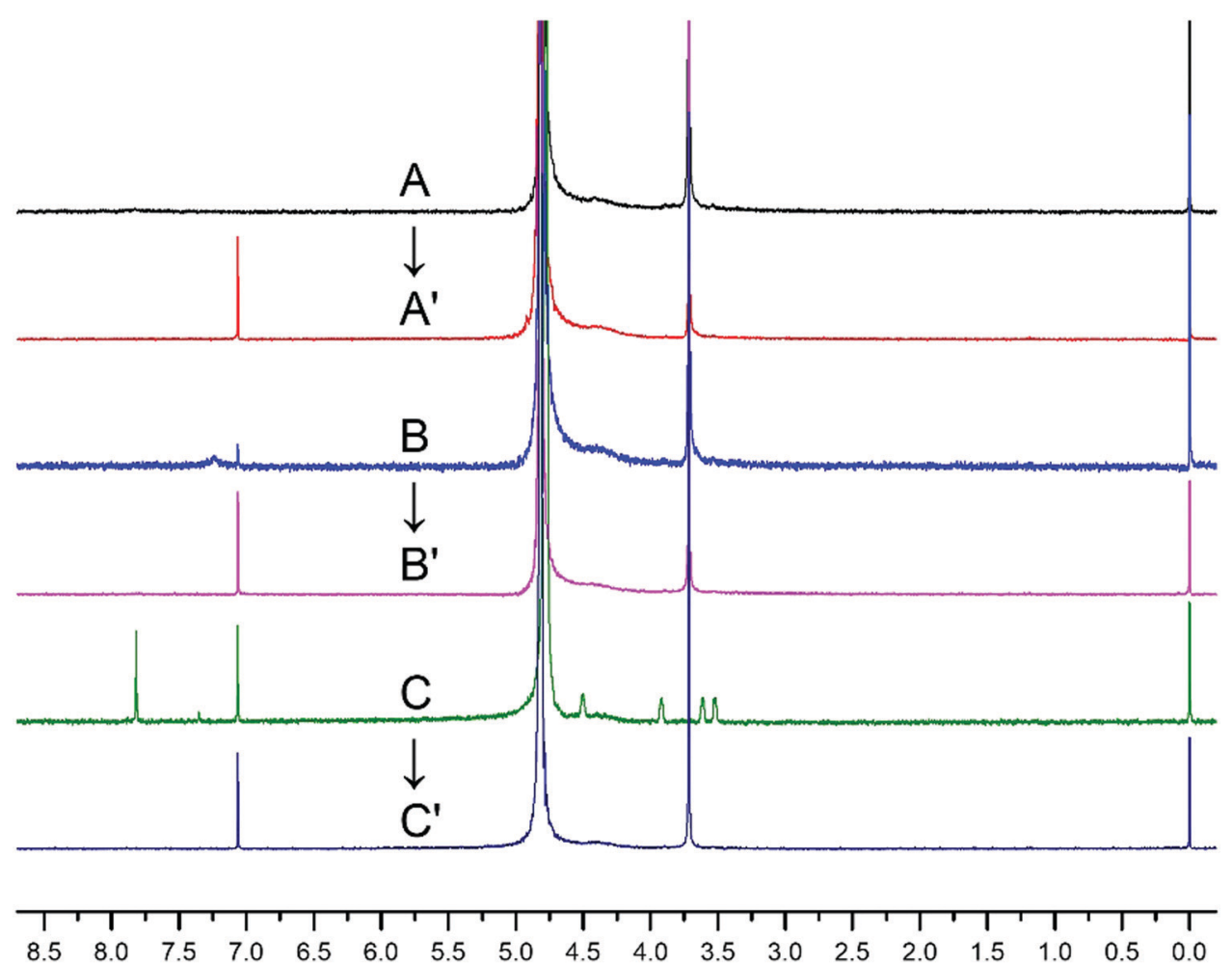

Fig. $4{ }^{1} \mathrm{H}$ NMR spectra of different $\mathrm{Zn}-\mathrm{C} 3 \mathrm{Ms}$ and mixtures. All samples were prepared in $\mathrm{D}_{2} \mathrm{O}$ under the designed combination with TSP as an internal standard. 
Table 2 Fractions of free DPA and LEO in different $\mathrm{Zn}-\mathrm{C} 3 \mathrm{Ms}$ and mixture solutions. The calculation is based on the ${ }^{1} \mathrm{H}$-NMR spectrum with TSP as an internal indicator. "I" indicates no NMR signals due to the absence of the compound and "-" means hardly detectable integral. For calculation details, see the ESI

\begin{tabular}{lllllll}
\hline & $\mathrm{A}$ & $\mathrm{A}^{\prime}$ & $\mathrm{B}$ & $\mathrm{B}^{\prime}$ & $\mathrm{C}$ & $\mathrm{C}^{\prime}$ \\
\hline DPA & $/$ & $99 \%$ & - & $96 \%$ & $90 \%$ & $91 \%$ \\
LEO & - & - & - & - & $93 \%$ & -
\end{tabular}

all the bis-ligand LEO is taken up in the micellar core, while 91\% DPA is free in the solution. Combining the light scattering and NMR results, we conclude that LEO is essential for the micellization of $\mathrm{Zn}-\mathrm{C} 3 \mathrm{Ms}$ as well. ${ }^{27,28}$

To avoid any further speculation, we add additional preparation routes $\mathrm{D}$ and $\mathrm{D}^{\prime}$, that is, we first mix DPA, LEO and BP together, then add metal ions, $\mathrm{La}$ or $\mathrm{Zn}$ into the mixture. Samples were prepared by the same strategy as that of the previous scenarios (A, B, and C; see the experimental part). As shown in Fig. S12 (ESI $\dagger$ ), mixture D indicates no micelle formation, and $\mathrm{D}^{\prime}$ displays comparable intensity with $\mathrm{A}^{\prime}$, for both La- and $\mathrm{Zn}$-based micelles, confirming the results from A, B and C scenarios, that is, LEO is indeed essential for micelle formation.

In Scheme 3, we explain the strategy for studying metal (zinc-lanthanide) exchange of M-C3Ms. For the lanthanide, we select $\mathrm{Eu}^{3+}$ this time because $\mathrm{Eu}^{3+}$ and $\mathrm{La}^{3+}$ show similar coordination chemistry with LEO, and provide micelles with comparable intensity and radius ${ }^{29,30}$ (Fig. 1a, A and Fig. 5a, X). In addition, $\mathrm{Eu}^{3+}$ has the useful feature that its fluorescence can be applied to investigate the internal coordination structure in the micelles. ${ }^{31,32}$ We fixed the LEO amount in all micellar solutions, implying that the $\mathrm{Zn} / \mathrm{Eu}$ ratio must be kept at $3 / 2$, so that both $\mathrm{Zn}^{2+}$ and $\mathrm{Eu}^{3+}$ can be fully coordinated with LEO, and can then form linear and network structures,

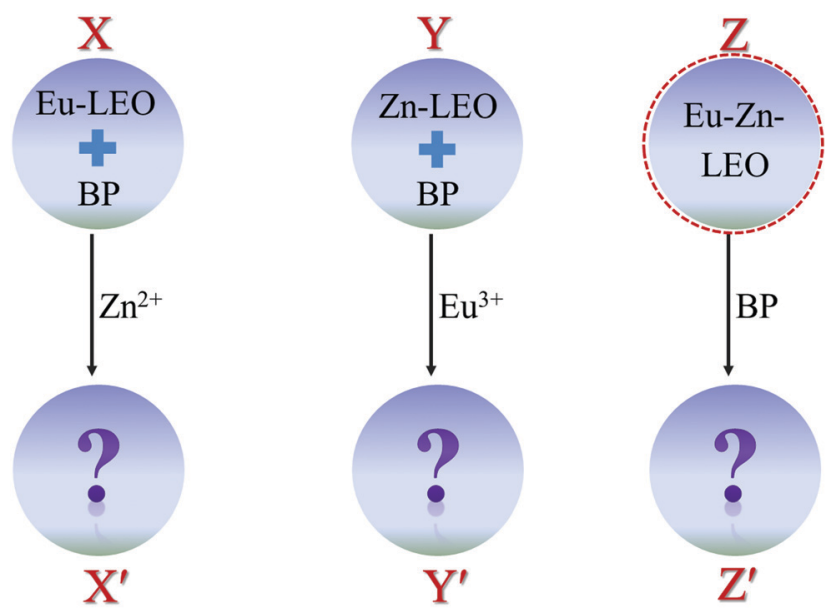

Scheme 3 Different scenarios to investigate $Z n-E u$ metal exchange of M-C3Ms. $X$ and $Y$ start with the designed micelles in solution, while the $Z$ mixture (dotted circles) only forms coordination structures without adding BP. Micelles were prepared based on a similar method to the ABC scenario, see details in the ESI. $\dagger$ respectively. For scenario X, Eu-C3Ms are prepared first, and then $\mathrm{Zn}^{2+}$ is added into the solution. Alternatively, Zn-C3Ms can be prepared (Y) followed by adding $\mathrm{Eu}^{3+}$ into the solution $\left(\mathrm{Y}^{\prime}\right)$. In scenario $\mathrm{Z}$, we first mix $\mathrm{Zn}^{2+}, \mathrm{Eu}^{3+}$ and LEO together, which gives no intensity and accessible size, confirming that only free coordination structures form in the mixture. Note that it is difficult to get well-resolved ${ }^{1} \mathrm{H}$ NMR spectra of these complexes as the paramagnetic properties of $\mathrm{Eu}^{3+}$ disturb the NMR signals. $^{33}$ It is only with the added BP $\left(\mathrm{Z}^{\prime}\right)$ that we obtain intensity and size information, as well as ${ }^{1} \mathrm{H}$ NMR spectra due to the uptake of $\mathrm{Eu}^{3+}$ in the micelles. Fig. 5 shows that the intensity and hydrodynamic radius of Eu-C3Ms hardly change after introducing $\mathrm{Zn}^{2+}$ into the solution. Compared with Eu-C3Ms, Zn-C3Ms have a higher intensity and bigger size. After adding $\mathrm{Eu}^{3+}$, both the intensity and radius decrease. Scenario $\mathrm{Z}^{\prime}$ ends with a similar intensity and size as that of $\mathrm{X}^{\prime}$.

The following experiments exploit different techniques in order to understand the $\mathrm{Zn}$-Eu exchange and variations in light scattering data in more detail. First of all, the ${ }^{1} \mathrm{H}$ NMR spectra in Fig. 7 confirm that no LEO is released in any of the mixture solutions, indicating that the supposed exchange could only have happened between $\mathrm{Zn}^{2+}$ and $\mathrm{Eu}^{3+}$ metal ions (Fig. S8-S10, ESI $\dagger$ ). We expect that the excess metal ions are free in the solution; in order to prove that, we centrifuged the mixture gently (2000 rpm, $5 \mathrm{~min}$ ) in the tube with a cut-off membrane that allows the metal ions to pass through but retains the micelles. The metal concentration in the filtrate was analyzed with ICP-AES. For Eu-C3Ms, around $3 \% \mathrm{Eu}^{3+}$ (mole fraction with respect to the overall amount) appears in the filtrate; obviously, no $\mathrm{Zn}^{2+}$ (II) ions are found there (Fig. 6a, X). In the case of Eu-C3Ms with added $\mathrm{Zn}^{2+}$, we find that around $29 \% \mathrm{Eu}^{3+}$ and $50 \% \mathrm{Zn}^{2+}$ are present in the filtrate $\left(\mathrm{X}^{\prime}\right)$. For $\mathrm{Zn}-\mathrm{C} 3 \mathrm{Ms}(\mathrm{Y})$, around $9 \% \mathrm{Zn}^{2+}$ is found after centrifugation. Adding $\mathrm{Eu}^{3+}$ to these micelles $\left(\mathrm{Y}^{\prime}\right)$ leads to amounts of $31 \% \mathrm{Eu}^{3+}$ and $49 \% \mathrm{Zn}^{2+}$, respectively, in the filtrate; these values are similar to those of mixtures $X^{\prime}$ and $Z^{\prime}$. All these findings suggest that the metal ions in the micellar core can exchange with those in the solution. The light scattering intensity responds, too, which may have many possible reasons. The micelles eventually contain $70 \% \mathrm{Eu}^{3+}$ and $50 \% \mathrm{Zn}^{2+}$ for all three final mixtures. In other words, $50 \% \mathrm{Zn}^{2+}$ can replace $30 \% \mathrm{Eu}^{3+}$ in the micelle. At the end of the exchange experiments, the overall compositions in all systems are the same, and the metal partitioning between micelle and solution is almost the same, but the sizes are still different. Apparently, there is incomplete equilibration, and the size of the micelles is partly controlled by kinetic factors. The $\mathrm{Zn}$-Eu exchange is confirmed by fluorescence. We fix the excitation wavelength at $275 \mathrm{~nm}$, where the DPA groups on LEO are excited, transferring their energy to $\mathrm{Eu}^{3+}$, which leads to emission (FRET effect). ${ }^{34,35}$ Since this energy transfer only happens when $\mathrm{Eu}^{3+}$ is in close proximity to DPA groups on LEO, the fluorescence intensity decay after adding $\mathrm{Zn}^{2+}$ to Eu-C3Ms ( $\mathrm{X}^{\prime}$, Fig. 6b) can be assigned to the breaking of the Eu-LEO contacts. Other scenarios end in similar fluorescence intensities $\left(\mathrm{Y}^{\prime}\right.$ and $\left.\mathrm{Z}^{\prime}\right)$, which agrees with the ICP data, suggesting that different mixing scenarios lead to similar final metal compositions in the micelles. 

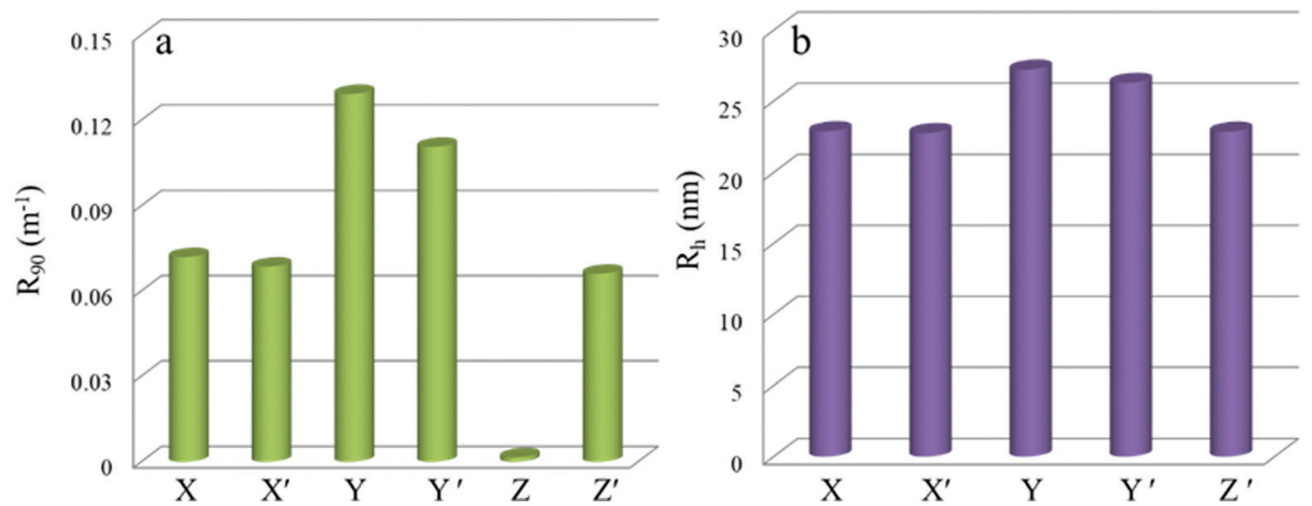

Fig. 5 Light scattering intensity (a) and hydrodynamic radius (b) of different M-C3Ms and mixtures. Mixture $Z$ contains coordination complexes but no micelles, so no size information is recorded in (b).
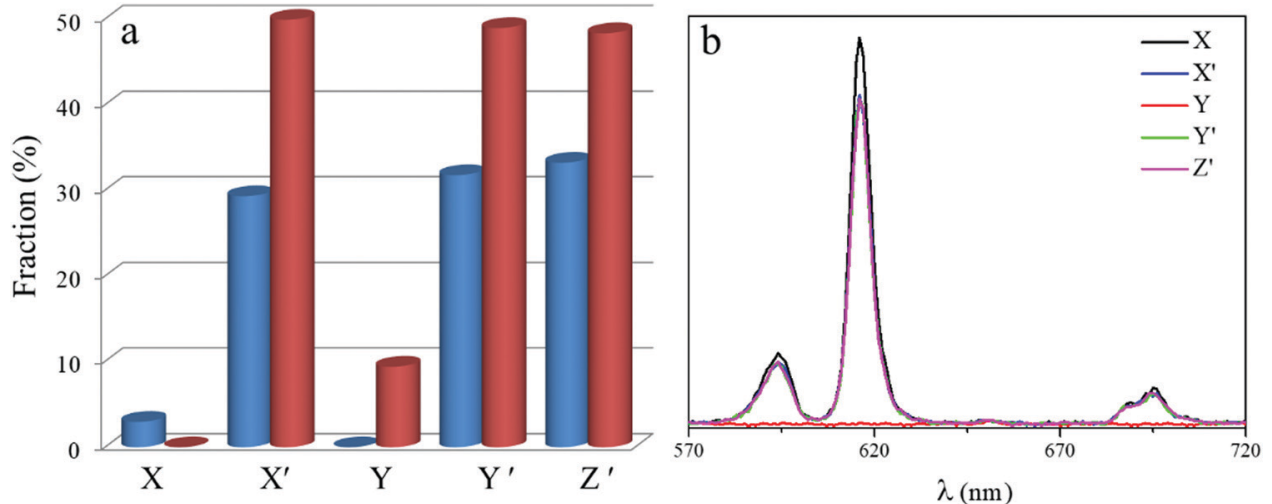

Fig. 6 Free metal concentration (a) and fluorescence emission (b) of different M-C3Ms and mixtures. The blue and red columns represent Eu and Zn fractions, respectively. Note that the mixture Z contains only Zn-Eu-LEO coordination structures, but no micelles, so neither the filtration, nor the followed ICP and fluorescence tests were performed.

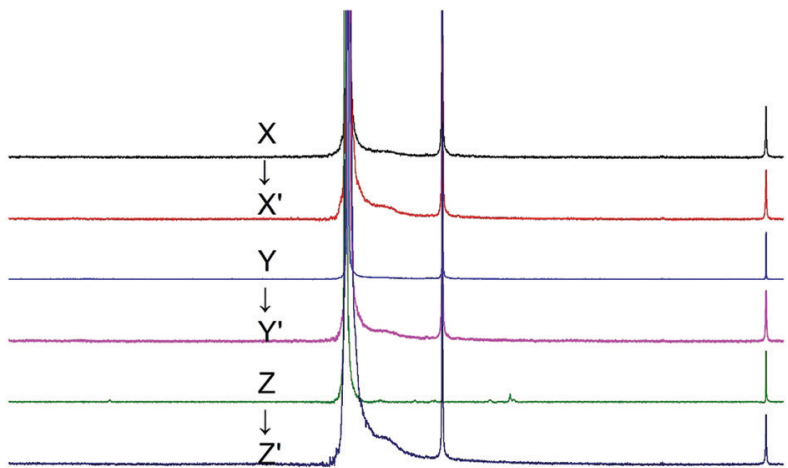

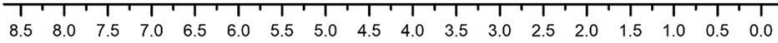

Fig. $7{ }^{1} \mathrm{H}$ NMR spectra of different M-C3Ms and mixtures. All samples were prepared in $\mathrm{D}_{2} \mathrm{O}$ under the designed combination with TSP as an internal standard.

\section{Conclusions}

In conclusion, we have investigated the responses of M-C3Ms to added ligand and metal ions. For both Ln-C3Ms and Zn-C3Ms, the bis-ligand LEO is essential for the growth of coordination polymers and the formation of micelles. Adding the monoligand DPA has no effect on M-C3Ms. This has implications for the use of such micelles in vivo: since small biomolecules can hardly bind with metal ions as much as the terdentate DPA does, we tentatively conclude that M-C3Ms are stable enough to survive in biological fluids. We also find that added $\mathrm{Zn}^{2+}$ can replace some $\mathrm{Ln}^{3+}$ from $\mathrm{Ln}-\mathrm{C} 3 \mathrm{Ms}$, and the released lanthanide ions may constitute a risk for bio-applications. However, the typical concentration of coordinating metal ions like $\mathrm{Cu}^{2+}$ or $\mathrm{Zn}^{2+}$ in biological fluids is so small that the risk is presumably negligible. Together with the excellent magnetic and fluorescence properties, we think that Ln-C3Ms are promising imaging probes for in vivo bio-applications. Moreover, we find that charge driven assembly has the ability to selectively take up the stronger binding component, which could be the case for classical organic macromolecular polyelectrolyte systems as well. These initial findings are just the tip of the iceberg to be revealed and further investigations are required to gain insight into the complex dynamic behaviour of polyelectrolyte micelles, in particular regarding the core subcomponent exchange. Studies on thermodynamic and kinetic aspects, as well as exchange under non-stoichiometric and non-equilibrium conditions, with more 
complex mixtures of metal ions, are just a few of the interesting next steps to investigate.

\section{Conflicts of interest}

There are no conflicts to declare.

\section{Acknowledgements}

This work was financially supported by the Shanghai Municipal Natural Science Foundation (17ZR1440500) and the Fundamental Research Funds for the Central Universities (222201714003).

\section{References}

1 D. V. Pergushov, A. H. E. Muller and F. H. Schacher, Chem. Soc. Rev., 2012, 41, 6888-6901.

2 W. J. Zhou, J. H. Wang, P. Ding, X. H. Guo, M. A. C. Stuart and J. Y. Wang, Angew. Chem., Int. Ed., 2019, 58, 8494-8498.

3 A. Harada and K. Kataoka, Macromolecules, 1995, 28, 5294-5299.

4 A. V. Kabanov, T. K. Bronich, V. A. Kabanov, K. Yu and A. Eisenberg, Macromolecules, 1996, 29, 6797-6802.

5 J. F. Gohy, S. K. Varshney, S. Antoun and R. Jerome, Macromolecules, 2000, 33, 9298-9305.

6 I. K. Voets, A. de Keizer and M. A. Cohen Stuart, Adv. Colloid Interface Sci., 2009, 147-148, 300-318.

7 H. E. Cingil, E. B. Boz, J. Y. Wang, M. A. C. Stuart and J. Sprakel, Adv. Funct. Mater., 2016, 26, 1420-1427.

8 S. van der Burgh, A. de Keizer and M. A. Cohen Stuart, Langmuir, 2004, 20, 1073-1084.

9 E. Spruijt, A. H. Westphal, J. W. Borst, M. A. C. Stuart and J. van der Gucht, Macromolecules, 2010, 43, 6476-6484.

10 R. Chollakup, J. B. Beck, K. Dirnberger, M. Tirrell and C. D. Eisenbach, Macromolecules, 2013, 46, 2376-2390.

11 M. K. Ma, B. Ahsan, J. H. Wang, M. W. Wang, X. H. Guo, M. A. C. Stuart and J. Y. Wang, Soft Matter, 2019, 15, 8210-8218.

12 Y. Anraku, A. Kishimura, M. Kamiya, S. Tanaka, T. Nomoto, K. Toh, Y. Matsumoto, S. Fukushima, D. Sueyoshi, M. R. Kano, Y. Urano, N. Nishiyama and K. Kataoka, Angew. Chem., Int. Ed., 2016, 55, 560-565.

13 D. Sueyoshi, Y. Anraku, T. Komatsu, Y. Urano and K. Kataoka, Biomacromolecules, 2017, 18, 1189-1196.

14 J. Y. Wang, A. de Keizer, R. Fokkink, Y. Yan, M. A. Cohen Stuart and J. van der Gucht, J. Phys. Chem. B, 2010, 114, 8313-8319.

15 Y. Yan, N. A. M. Besseling, A. de Keizer, A. T. M. Marcelis, M. Drechsler and M. A. Cohen Stuart, Angew. Chem., Int. Ed., 2007, 46, 1807-1809.

16 J. Y. Wang, A. de Keizer, H. P. van Leeuwen, Y. Yan, F. Vergeldt, H. van As, P. H. H. Bomans, N. Sommerdijk,
M. A. C. Stuart and J. van der Gucht, Langmuir, 2011, 27, 14776-14782.

17 J. Y. Wang, A. Groeneveld, M. Oikonomou, A. Prusova, H. Van As, J. W. M. van Lent and A. H. Velders, Soft Matter, 2016, 12, 99-105.

18 J. Wang, S. Sun, B. Wu, L. Hou, P. Ding, X. Guo, M. A. Cohen Stuart and J. Wang, Macromolecules, 2019, 52, 8643-8650.

19 J. H. Wang, J. Y. Wang, P. Ding, W. J. Zhou, Y. H. Li, M. Drechsler, X. H. Guo and M. A. C. Stuart, Angew. Chem., Int. Ed., 2018, 57, 12680-12684.

20 K. J. Li, J. X. Wei, H. B. Yu, P. Y. Xu, J. H. Wang, H. F. Yin, M. A. C. Stuart, J. Y. Wang and S. H. Zhou, Angew. Chem., Int. Ed., 2018, 57, 16458-16463.

21 J. Y. Wang, M. A. C. Stuart and J. van der Gucht, Macromolecules, 2012, 45, 8903-8909.

22 T. Vermonden, J. van der Gucht, P. de Waard, A. T. M. Marcelis, N. A. M. Besseling, E. J. R. Sudholter, G. J. Fleer and M. A. C. Stuart, Macromolecules, 2003, 36, 7035-7044.

23 A. Hernandez-Garcia, A. H. Velders, M. A. C. Stuart, R. de Vries, J. W. M. van Lent and J. Y. Wang, Chem. - Eur. J., 2017, 23, 239-243.

24 J. N. Huang, J. Wang, P. Ding, W. Zhou, L. Liu, X. Guo, M. A. C. Stuart and J. Y. Wang, Macromolecules, 2019, 52, 1874-1881.

25 C. Facciotti, V. Saggiomo, A. Bunschoten, R. Fokkink, J. B. ten Hove, J. Y. Wang and A. H. Velders, Soft Matter, 2018, 14, 9542-9549.

26 C. Facciotti, V. Saggiomo, S. van Hurne, A. Bunschoten, R. Kaup and A. H. Velders, Supramol. Chem., 2020, 32, 30-38.

27 Y. Yan, N. A. M. Besseling, A. de Keizer and M. A. C. Stuart, J. Phys. Chem. B, 2007, 111, 5811-5818.

28 Y. Yan, A. de Keizer, M. A. Cohen Stuart, M. Drechsler and N. A. M. Besseling, J. Phys. Chem. B, 2008, 112, 10908-10914.

29 J. C. G. Bunzli and C. Piguet, Chem. Rev., 2002, 102, 1897-1928.

30 J. Y. Wang, A. H. Velders, E. Gianolio, S. Aime, F. J. Vergeldt, H. Van As, Y. Yan, M. Drechsler, A. de Keizer, M. A. Cohen Stuart and J. van der Gucht, Chem. Commun., 2013, 49, 3736-3738.

31 A. S. Chauvin, F. Gumy, D. Imbert and J. C. G. Bunzli, Spectrosc. Lett., 2004, 37, 517-532.

32 L. M. Xu, Y. Y. Jing, L. Z. Feng, Z. Y. Xian, Y. Yan, Z. Liu and J. B. Huang, Phys. Chem. Chem. Phys., 2013, 15, 16641-16647.

33 T. Vermonden, W. M. de Vos, A. T. M. Marcelis and E. J. R. Sudholter, Eur. J. Inorg. Chem., 2004, 2847-2852.

34 M. D. Yilmaz, S. H. Hsu, D. N. Reinhoudt, A. H. Velders and J. Huskens, Angew. Chem., Int. Ed., 2010, 49, 5938-5941.

35 J. Y. Wang, M. A. C. Stuart, A. T. M. Marcelis, M. ColombDelsuc, S. Otto and J. van der Gucht, Macromolecules, 2012, 45, 7179-7185. 